\title{
Buying seafood: Understanding barriers to purchase across consumption segments
}

\author{
D. Birch ${ }^{\mathrm{a} *}$, M. Lawley ${ }^{\mathrm{a}}$ \\ ${ }^{a}$ Faculty of Business, University of the Sunshine Coast, Maroochydore DC, Queensland, \\ 4558, Australia. E-mail addresses: dbirch@usc.edu.au and mlawley1@usc.edu.au
}

*Corresponding author. E-mail address: dbirch@usc.edu.au Telephone: +61 0754301223

Fax: +61 0754301210

\begin{abstract}
Most consumers have positive attitudes toward seafood and consider it to be an important part of a healthy and balanced diet. However when purchasing seafood, consumers also weigh up various risks which may act as barriers to consumption. In this paper, the findings of an online survey of Australian consumers $(\mathrm{n}=899)$ which explored both drivers and barriers to seafood consumption are discussed. The primary focus of this paper is to explore the perceived risks of seafood consumption and how these vary across consumption levels. Perceived risks associated with seafood consumption include functional, social, physical, psychological, and financial risk. With the exceptions of physical and financial risk, perceptions of risk varied across regular, light and very light seafood consumption segments. Lighter fish consumers were more likely to perceive functional risk associated with being less informed and less familiar with fish, experience more difficulties with selecting fish, recognising if fish is fresh, and preparing and serving fish than more regular fish consumers. Regular seafood consumers were less likely than lighter seafood consumers to perceive social risk arising from other members of their household not liking fish. Moreover, regular seafood consumers were less likely to perceive psychological risks associated with unpleasant past experiences or unpleasant sensory qualities, such as not liking the smell of fish and not liking to touch fish. Based on these results strategies for reducing perceived risks as a means of stimulating fish consumption are proposed for further investigation.
\end{abstract}

Keywords: Seafood; Fish; Consumption; Barriers; Perceived Risk; Segments

\section{Introduction}

Despite an abundance of seafood being available in Australia and the significant physical and mental health benefits associated with seafood consumption, many Australians consume less than the recommended levels of two serves per week (Heart Foundation, 2012). Unlike many European and Asian countries, seafood is not a part of the traditional Australian diet, thus many Australians are not in the habit of regularly consuming seafood. Seafood consumption in Australia is slowly increasing at an average of 2.2 weekly serves per capita in 2011; however, it still remains well below many other industrialised nations (Danenberg \& 
Mueller, 2011). While there has been a substantial amount of research on drivers and barriers to seafood consumption in European countries, where per capita seafood consumption is customarily higher, there is limited research about seafood consumption in western countries, such as Australia. Key drivers to seafood consumption in Australia have been identified as taste, convenience, diet variety and health benefits and these serve to overcome some of the barriers to seafood consumption (Birch \& Lawley, 2010; Sioen, Van Camp, Verdonck, Verbeke, Vanhonacker. \& Willems, 2007). However, the main purpose of this paper is to focus on the perceived risks of seafood consumption resulting in barriers to consumption, and to explore whether perceptions of risk varies across consumption levels. Research has revealed that barriers to seafood consumption are more evident with lighter or less experienced seafood consumers than with regular or more experienced seafood consumers (Olsen, 2004; Pieniak, Verbeke, Vermeir, Brunsø, \& Olsen, 2008; Sogn-Grundvåg \& Ostli, 2009). Based on an understanding of barriers to seafood consumption in Australia, we propose strategies for further investigation that may reduce these perceived risks and thus stimulate seafood consumption, in particular for lighter seafood consumers.

In this paper, we commence with a discussion of the role of perceived risk in influencing seafood consumption and various types of perceived risk. Next, we present the research aims and hypotheses. The methodology involving an online consumer survey is described and the data analysis conducted is explained. The results are presented and findings discussed. We conclude with the identification of possible strategies for reducing the perceived risks of seafood consumption for further investigation.

\subsection{The role of perceived risk in influencing seafood consumption}

Perceived risk from a consumer behaviour perspective relates to the degree of uncertainty and the potential for important negative consequences for the consumer arising from a poor purchasing decision (Bauer, 1960; Cho \& Lee, 2006; Dowling \& Staelin, 1994; Tuu \& Olsen, 2009). Perceptions of risk from making poor purchasing decisions are a strong predictor of consumption behaviour (Mitchell, 1999; Tuu \& Olsen, 2009). When the relative importance or significance of potential negative consequences is high, perceived risk is greater (Taylor, 1974). For example, despite seafood being, in actuality, a relatively safe product to consume, people can die as a result of eating seafood (Bean \& Griffen, 1990). While risk has a known probability, uncertainty emerges when the consumer does not know the precise probability of the risk occurring (Knight, 1948). However, from a marketing perspective, Cunningham (1967) argued that it makes no difference to the consumer whether the precise probability is known or unknown, and it is perceived uncertainty rather than actual risk that influences purchasing behaviour (Mitchell, 1999). The term risk, as used in this paper, includes this uncertainty.

Perceived risk is important to marketers as it influences pre-purchase attitudes, evaluations and intentions, as well as, post-purchase evaluations, satisfaction and loyalty (Campbell \& Goldstein, 2001; Chen \& Li, 2007; Grewal, Gopalkrisnan, Gotlieb, \& Levy, 2007; Gurhan-Canli \& Batra, 2004; Park, Lennon, \& Stoel, 2005; Tuu \& Olsen, 2009; Yuksel $\&$ Yuksel, 2006). Perceived risk is closely linked to the level of involvement in the buying decision making process due to the complexity of considerations involved (Laurent \& Kapferer, 1985). The degree of involvement concerns the relative importance of the product to the consumer and the extent to which making the right product choice is important (Zaichowsky, 1985). Where involvement is high, consumers will take more time and devote more effort to arrive at the right purchasing decision. As a rule, food is a product where involvement is low and thus decision making tends to be associated with limited, habitual or routine response behaviour (Blackwell, Miniard, \& Engel, 2001; Mahon, Cowan, \& 
McCarthy, 2006). However, the perceived risks associated with making the wrong decision when purchasing seafood makes seafood a product where involvement is higher than with many other food items (Fischer \& Frewer, 2009; Foxall, Leek, \& Maddock, 1998; Juhl \& Poulsen, 2000; Pieniak et al., 2008; Vanhonacker, Pieniak \& Verbeke, 2010). The greater the perceived risk, the more involved the consumer becomes in the decision making process, and the more extensive is the search for both personal and non-personal information during evaluation of alternatives (Bansal \& Voyer, 2000; Cho \& Lee, 2006; Dowling \& Staelin, 1994; Gurhan-Canli \& Batra, 2004). Mitchell (1999) argued "perceived risk is more powerful at explaining consumers' behaviour since consumers are more often motivated to avoid mistakes than maximise utility in purchasing” (p. 163).

\subsection{Types of perceived risk associated with seafood consumption and variation across consumption segments}

Numerous studies have focussed on the perceived risk of purchasing food products (Mitchell, 1999). Various types of perceived risks faced by consumers in the buying decision have been identified and can be applied to seafood consumption including functional, social, physical, psychological and financial risks (McCathy \& Henson, 2005; Stone \& Gronhaug, 1993; Tsiros \& Heilman, 2005). These risks have been found to vary across consumption segments with lighter seafood consumers experiencing higher levels of perceived risk than more regular seafood consumers (Olsen, 2004; Pieniak et al., 2008; Sogn-Grundvåg \& Ostli, 2009; Vanhonacker et al., 2010).

\subsubsection{Functional risk associated with seafood consumption}

Functional risk arises when a product may not perform up to expectations. Functional risk is associated with the consumers' degree of familiarity, knowledge and confidence with a product category which, in turn, influences the degree of involvement in the decision making processes of information search, evaluation of alternatives and purchase decisions (Howard \& Sheth, 1969; Myrland, Trondsen, Johnston, \& Lund, 2000; Verbeke, Vanhonacker, Frewer, Sioen, DeHenauw, \& Van Vamp, 2008). The more familiar and knowledgeable the consumer is with the product category, the greater the confidence or degree of self-efficacy they perceive to make the right purchasing decision, and thus reduce functional risk (SognGrundvåg \& Ostli, 2009). Knowledge about seafood is closely related to the consumers' past experiences and their degree of familiarity with seafood leading to a level of expertise (Fischer \& Frewer, 2009; Pieniak et al., 2008; Tuu \& Olsen, 2009). Olsen (2004) explains that knowledge about seafood increases the consumer's ability to manage the entire seafood consumption process from selection to serving. Consumer knowledge is also brought to bear in making risk assessments, with customers with lower levels of knowledge or expertise experiencing higher levels of perceived risk due to uncertainty (Frewer, Shepherd, \& Sparks, 1994; Klerch \& Sweeney, 2007; Laroche, Nepomuceno, \& Richard, 2010). Self-efficacy refers to how competent a person feels to do what is required to manage a situation, and thus reduce uncertainty (Bandura, 1997). In the case of seafood, self-efficacy relates to the consumers' confidence in making a good choice when selecting, storing, and preparing seafood.

Previous studies of seafood consumption have revealed the unsurprising fact that many consumers, and in particular less regular, less experienced and less knowledgeable seafood consumers, experience difficulty in evaluating, selecting, and preparing seafood (Bruns $\varnothing$, Verbeke, Olsen, \& Jeppesen, 2009; Juhl \& Poulsen, 2000; Scholderer \& Grunert, 2001; Sogn-Grundvåg \& Ostli, 2009; Sveinsdóttir, Martinsdottir, Green-Petersen, Hyldig, Schelvis, \& Delahunty, 2009). Seafood is a food category that requires acquisition of sensory 
skills and a lack of sensory ability by consumers to evaluate the quality of seafood or determine whether seafood is fresh has been found to be a major barrier to seafood consumption and to vary across consumption segments (Olsen, 2004; Verbeke \& Vackier, 2005; Verbeke, Sioen, Pieniak, Van Camp, \& De Henauw, 2005).

\subsubsection{Social risk associated with seafood consumption}

Social risk arises from social norms due to a potential lack of acceptance from significant others. Social norms or pressure from household members who do not like to eat seafood have been found to negatively influence seafood consumption (Olsen, 2001; Olsen, 2004; Scholderer \& Grunert, 2001; Trondsen, Scholderer, Lund, \& Eggen, 2003 Verbeke \& Vackier, 2005). In particular, the presence of children and teenagers within the household has been found to result in lower levels of seafood consumption (Honkanen, Olsen, \& Myrland, 2004; Myrland et al., 2000; Olsen \& Ruiz, 2008). Indeed, family expectations, both positive and negative, have been found to be as influential as attitudinal factors such as taste and preferences in explaining levels of seafood consumption (Bredahl \& Grunert, 1997; Olsen, 2001, Verbeke \& Vackier, 2005).

\subsubsection{Physical risk associated with seafood consumption}

Safety and minimising risk or hazardous outcomes have been found to be important aspects of food consumption (Bredbenner, Mauer, Wheatly, Cottone, \& Clancy, 2007; Fischer \& Frewer, 2009; Tuu \& Olsen, 2009). Perceived risk associated with seafood consumption pertains to issues of safety, with some consumers being concerned about possible contaminants, treatment with hormones or antibiotics, mercury levels and whether the seafood has been handled in a hygienic manner (Lobb, Mazzocchi, \& Traill, 2007; Sioen et al.,2007; Verbeke et al., 2005; Vanhonacker et al. 2010). Seafood consumers, and in particular those in high risk groups such as young children and pregnant women, may perceive physical risk or risk to their well-being or health, such as choking on a fish bone or unacceptable levels of mercury (Jardine \& Bunn, 2010). Lower levels of seafood consumption have been associated with perceptions of physical risk associated with food poisoning from eating seafood (Pieniak et al., 2008; Vanhonacker, et.al., 2010).

\subsubsection{Psychological risk associated with seafood consumption}

Unpleasant past experiences with seafood consumption and perceptions of unpleasant sensory qualities of seafood such as unpleasant smells, not liking the taste or texture of seafood, not liking to touch seafood, and the presence of bones in fish gives rise to psychological risk and have been found to be a major barrier to seafood consumption (Bredahl \& Grunert, 1997; Brunsø et al., 2009; Leek, Maddock, \& Foxall, 2000; Olsen, 2001; Olsen, 2003; Olsen, 2004; Rortveit \& Olsen, 2009; Verbeke \& Vackier, 2005). Seafood consumption studies have found that some consumers, and in particular less experienced seafood consumers perceive more barriers to seafood consumption including the presence of unpleasant sensory qualities (Baird, Bennett, \& Hamilton, 1988; Bruns $\varnothing$ et al., 2009; Myrland et al., 2000; Nielsen, Hyldig, \& Larsen, 2002; Trondsen et al., 2003; Vanhonacker et al., 2010). 


\subsubsection{Financial risk associated with seafood consumption}

Financial risk associated with seafood consumption may arise with seafood being perceived to be a relatively expensive meal option (Brunsø et al., 2009; Myrland et al., 2000; Olsen, 2004; Trondsen et al., 2003; Verbeke \& Vackier, 2005). The potential for financial loss is exacerbated due to functional risk with the possibility of spoiling the seafood during storage or preparation resulting from a lack of consumer knowledge or confidence, and hence more likely to be associated with less experienced seafood consumers (Sogn-Grundvåg \& Ostli, 2009). Previous research has revealed that seafood experts are less price sensitive than less skilled seafood consumers (Arvanitoyannis \& Krystallis, 2005; Bruns $\varnothing$ et al., 2009; Hanson, Rauniyar, \& Herrmann, 1994; Verbeke, Vermeir, \& Brunsø, 2007).

\subsection{Strategies for reducing the perceived risk of seafood consumption}

Seafood consumers may use three key strategies (risk relievers) to reduce the perceived risks associated with seafood consumption (Angulo \& Gil, 2007). First, they may purchase a familiar, trusted and well-known product or brand (Campbell \& Goldstein, 2001; Lobb et al., 2007). The inherent risk in a product category, such as seafood, may be mitigated to some extent by purchasing a well-known and trusted brand or from a reputable seafood supplier (Bettman, 1973; Mitchell, 1999).

Second, seafood consumers may seek out trustworthy and useful information on less familiar product offerings (Pieniak, Verbeke, Vermeir, Bruns $\varnothing, \&$ Olsen, 2007a; Taylor, 1974). When faced with high perceived risk or product incongruity, consumers tend to demonstrate a preference for the norm; that is, favour familiar products over less familiar products (Campbell \& Goldstein, 2001). Indeed, previous seafood consumption studies have argued that Australian consumers hold strong preferences for Australian seafood and for a particular species of fish, and prefer to purchase and serve seafood with which they are familiar (Fisheries Research \& Development Corporation, 2006).

Third, a lack of ability to rely upon search characteristics and sensory qualities such as smell and touch when selecting fish in modern retail settings means that consumers rely more heavily on extrinsic cues and credence characteristics, in which they are required to place their trust in producers and retailers to provide accurate information and handle the fish in ways that minimise potential hazards (Cho \& Lee, 2006; Lobb et al., 2007; Pieniak, Verbeke, Vermeir, Bruns $\varnothing, \&$ Olsen, 2007b). Consumers use extrinsic cues such as price, outlets, origin, packaging, labelling, branding, and nutritional information to assist them to evaluate perceptions of fish quality and reduce perceived risk (Brunsø et al., 2009; Nielsen et al., 2002; Trondsen et al., 2003). Consumers may be prepared to for pay for assurances of quality and country of origin (Angulo \& Gil, 2007). Dimara and Skuras (2003) argue that issues related to certification, region of production and traceability are important quality cues with consumers being interested in purchasing products assured to be of high quality and authenticity.

\subsection{Aims and hypotheses}

The main aim of this paper is to investigate factors leading to perceived risk associated with seafood consumption and to determine whether perceptions of risk vary across consumption segments. Based on the extant literature, the following five hypotheses were developed and tested: Regular fish consumers are less likely than lighter fish consumers to perceive:

Hypothesis 1: functional risk associated with fish consumption. 
Hypothesis 2: social risk associated with fish consumption.

Hypothesis 3: physical risk associated with fish consumption.

Hypothesis 4: psychological risk associated with fish consumption.

Hypothesis 5: financial risk associated with fish consumption.

Based on the findings of the research and a review of the relevant literature, we propose strategies for further investigation that may reduce the perceived risk associated with seafood consumption and thus stimulate fish consumption, in particular for lighter seafood consumers.

\section{Materials and methods}

To investigate the research questions, a survey of Australian consumers $(n=899)$ was conducted with an online consumer panel of 60,000 active participants in June 2010. To prevent over-use of panellists and to ensure authentic membership by excluding 'professional respondents', a number of sophisticated validation methodologies are employed by the panel managers (Your Source, 2011). Participants were screened for industry affiliation, participation in recent seafood research in the past six months, age (18 years and older), whether they were either the main or joint grocery shopper in the household, and for having consumed fish in the past three months. The main purpose of the survey was to measure Australian seafood consumers' attitudes toward finfish consumption. Very few Australian consumers classify as 'heavy' finfish consumers. Hence, participants were selected and classified as being either regular $(n=296)$, light $(n=303)$ or very light $(n=300)$ fish consumers. Regular fish consumers are those who purchase and eat fish 2 - 3 times per week to at least once a week. Light fish consumers purchase and eat fish about once per fortnight, while very light fish consumers purchase and eat fish once per month.

Given the screening of participants based on main or joint grocery shopper, females represented 65.9 percent of the sample $(n=592)$ and males represented 34.1 percent $(n=307)$ (Table 1). Seventy-three percent of respondents were the main shopper and 27 percent identified as being the joint grocery shopper in their household. The respondent profile was compared with census data from the Australian Bureau of Statistics to determine representativeness of the sample (Australian Bureau of Statistics, 2011). Perhaps reflecting a greater interest in seafood as a research topic, the majority of the respondents from the online panel who elected to complete the survey were in the 55 years and older age bracket (34\%), with the next largest age bracket being 45 - 54 years (29.7\%), with respondents under 25 years of age being the smallest age group in this survey (2.7\%). Moreover, the sample was highly educated with the majority of respondents being tertiary educated (47.6\%), with the next largest group being technically trained $(27.3 \%)$, followed by people educated to secondary school level (24.1\%). This skewed age and educational range may mean that perceived barriers to fish consumption are under-reported in this study and this should be considered when interpreting the findings. For example, Trondsen et al. (2003) found a negative relationship between educational level and perceptions of barriers to fish consumption. Likewise, Verbeke and Vackier (2005) argued that older consumers hold more positive attitudes toward seafood consumption and experience less difficulty in preparing seafood. The respondents were represented across a broad and representative range of annual household income categories. 
Table 1

Respondent profile.

\begin{tabular}{llrr}
\hline \multicolumn{1}{c}{ Variable } & \multicolumn{1}{c}{ Level } & Sample & \multicolumn{1}{c}{ Population } \\
\hline Gender & Female & 65.9 & 50.6 \\
Age & Male & 34.1 & 49.4 \\
& 55 years and older & 34.0 & 24.8 \\
& $45-54$ & 29.7 & 13.6 \\
& $35-44$ & 20.1 & 14.2 \\
& $25-34$ & 13.5 & 14.3 \\
Education & $18-24$ & 2.7 & $7.4(20-24 \mathrm{yr})$ \\
& Tertiary /university & 47.6 & 23.0 \\
Annual household income (AUD) & Technical training/TAFE & 27.3 & 26.9 \\
& Secondary/Primary school & 25.1 & 50.0 \\
& 100,000 or above & 26.7 & 30.3 \\
& $60,000-99,999$ & 27.1 & 23.6 \\
& $20,000-59,999$ & 24.2 & 34.2 \\
& Less than 20,000 & 15.9 & 11.9 \\
\hline
\end{tabular}

Demographic differences across the three consumption groups (regular, light and very light) were not evident when tested with Chi-Square analysis, with the exception that older consumers (55 years plus) were more likely to be regular consumers of fish than younger consumers (18-24 years). Previous studies of seafood consumption have also revealed a positive relationship between age and seafood consumption (Myrland et al., 2000; Olsen, 2003, Trondsen et al., 2003; Verbeke \& Vackier, 2005). Trondsen et al. (2003) and Verbeke and Vackier (2005) also did not find any relationship between income and education with actual consumption frequency.

Just over half of the respondents $(51 \%)$ did not have children living at home, while 10 percent of respondents lived alone. The majority of respondents resided in the major capital cities of Melbourne (31.3\%) and Sydney (25\%). Respondents from other Australian capital cities and regional areas of Australia were under-represented in the sample.

\subsection{Measures}

Questions for the consumer survey were drawn from an extensive review of the literature on seafood consumption, and recent qualitative and quantitative research studies of seafood consumption in Australia conducted on behalf of the Australian Seafood Cooperative Research Centre. Scales and items for measuring constructs were based on ideas and items measured in a number of previous studies of seafood consumption and then adapted to the Australian context for this study. In particular, the specific content and wording of the items was informed by the findings of ten focus groups of seafood consumers that had been conducted across five states of Australia $(n=60)$ for another related study of seafood consumption that also focussed on drivers and barriers to seafood consumption in Australia. To avoid the clustering of responses at the neutral point or positive responses associated with social desirability, and to gain a clearer picture of the relative direction of attitudes, items were measured on either a six-point agreement or a six-point importance scale (Garland, 1991; Malhotra, 2004).

Functional risk was measured with seven items. First, to assess the extent to which respondents were familiar with and informed about fish, we drew from the work of Verbeke and Vackier (2005) and included two items "I am well informed about fish" and "I am 
familiar with preparing fish". To determine the extent to which Australian consumers perceived functional risk associated with a lack of knowledge or confidence to select and/or prepare fish, we developed a bank of items adapted from the work of a number of researchers (e.g., Pieniak et al., 2007a; Scholderer \& Grunert, 2001; Sørensen, Grunert, \& Nielsen, 1996; Sveinsdottir et al., 2009; Vanhonacker et al., 2010) and included the following five items: "I cannot recognise when fish is fresh", "I do not know how to select fish", "I do not know much about how to prepare and serve fish", "I can easily prepare tasty dishes from fish", and "Fish is easy to prepare and serve".

Social risk was measured with three items including two items adapted from Olsen's social norm scale (2001) "Resistance by other members of my household makes it difficult for me to serve fish as often as I want", and "Other adults in my household do not like fish". The focus groups had revealed that the presence of children in the household may influence seafood consumption, thus we included the statement, "One or more children in my household do not like fish".

Five items for measuring the physical risk of eating seafood were based on the literature regarding seafood safety, as well as concerns raised in the focus groups (e.g., Fischer \& Frewer, 2009; Vanhonacker et al., 2010; Verbeke \& Vackier, 2005; Verbeke et al., 2008). Items included "I am concerned about possible contaminants in fish", "I am concerned about high mercury levels in fish", "I am concerned that fish may not have been handled in a hygienic way", "I am concerned that fish may have been treated with hormones or antibiotics", and "Eating fish is risky".

Psychological risk was measured with seven items based on the focus group findings and previous studies conducted by Verbeke and Vackier (2005), Rortveit and Olsen (2009) and Olsen (2003). The scale included three statements related to past experiences with fish, "I have had good experiences in eating fish in the past", "Fish usually tastes bad", and "Eating fish is usually an unpleasant experience", and four statements associated with the unpleasant sensory qualities of fish, "I do not like the smell of fish when preparing it", "I do not like the smell of fish", "I do not like to touch fish", and "The bones in fish are unpleasant". Financial risk was simply measured on one item "Fish is an inexpensive meal option".

\subsection{Data Analysis}

Data were analysed using SPSS version 19.0. Means and standard deviations were calculated for each item. Confirmatory factor analysis with maximum likelihood extraction and oblimin rotation was conducted on the items. Cronbach's Alpha was conducted to test for item reliability. Analysis of variance was conducted to identify significant differences across consumption segments (regular, light and very light fish consumers). Demographic differences were also identified through analysis of variance and independent samples t-tests. Levene's test was used to check for homogeneity of variances and post-hoc tests (Tukey HSD) were used to determine the pattern of differences between groups. Differences were deemed significantly significant if the $p$-value was less than 0.05 .

\section{Results and discussion}

\subsection{Factor Analysis and Reliability Testing}

Confirmatory factor analysis revealed five factors with eigenvalues greater than 1.0 $\left(\mathrm{KMO}=0.880, \chi^{2}=10419.35\right.$, d.f. $\left.=231, \mathrm{p}=0.00\right)$. The single item measuring financial risk was very weakly correlated with the other factors and was excluded from the factor analysis. Items related to psychological risk loaded onto two separate factors with one being related to past experiences in consuming fish and the other related to the unpleasant sensory qualities of 
fish mainly associated with preparing fish. Cronbach's Alpha was conducted to test the internal reliability of the multi-item scales. The standardised factor loading coefficients and Cronbach's alpha coefficients are presented in table 2.

Table 2

Factor Analysis and Reliability Testing

\begin{tabular}{|c|c|c|c|}
\hline Construct/Items & $\begin{array}{l}\text { Variance } \\
\text { Explained }\end{array}$ & $\begin{array}{l}\text { Factor } \\
\text { Loadings }\end{array}$ & $\begin{array}{c}\text { Cronbach } \\
\text { alpha } \\
\text { coefficient }\end{array}$ \\
\hline Functional Risk & $30.5 \%$ & & 0.90 \\
\hline I do not know much about how to prepare and serve fish & & 0.82 & \\
\hline I am familiar with preparing fish & & -0.81 & \\
\hline I can easily prepare tasty dishes from fish & & -0.77 & \\
\hline I am well informed about fish & & -0.77 & \\
\hline I do not know how to select fish & & 0.76 & \\
\hline Fish is easy to prepare and serve & & -0.68 & \\
\hline I cannot recognise if fish is fresh & & 0.65 & \\
\hline Social Risk & $14.5 \%$ & & 0.80 \\
\hline $\begin{array}{l}\text { Resistance by other members of my household make it hard to serve } \\
\text { fish as often as I want }\end{array}$ & & 0.95 & \\
\hline Other adults in my household do not like fish & & 0.77 & \\
\hline One or more children in my household do not like fish & & 0.72 & \\
\hline Physical Risk & $9.5 \%$ & & 0.89 \\
\hline I am concerned about possible contaminants in fish & & 0.91 & \\
\hline I am concerned about high mercury levels in fish & & 0.81 & \\
\hline I am concerned that fish may not have been handled in a hygienic way & & 0.81 & \\
\hline $\begin{array}{l}\text { I am concerned that fish may have been treated with hormones or } \\
\text { antibiotics }\end{array}$ & & 0.78 & \\
\hline Eating fish is risky & & 0.61 & \\
\hline Psychological Risk - Unpleasant past experiences & $7.8 \%$ & & 0.75 \\
\hline Fish usually tastes bad & & 0.87 & \\
\hline Eating fish is usually an unpleasant experience & & 0.77 & \\
\hline I have had good experiences in eating fish in the past & & -0.49 & \\
\hline Psychological Risk - Unpleasant sensory qualities & $4.9 \%$ & & 0.74 \\
\hline I do not like the smell of fish when preparing it & & 0.85 & \\
\hline I do not like the smell of fish & & 0.79 & \\
\hline I do not like to touch fish & & 0.65 & \\
\hline The bones in fish are unpleasant & & 0.31 & \\
\hline
\end{tabular}

\subsection{Findings related to the functional risk of seafood consumption}

To assess the functional risk associated with a lack of familiarity with seafood or a lack of knowledge and confidence in selecting and preparing seafood, we asked respondents their level of agreement with seven statements, as presented in Table 3. 


\section{Table 3}

Perceptions of factors associated with the functional risk of fish consumption by usage segment

\begin{tabular}{lcccccc}
\hline \multicolumn{1}{c}{ Item } & $\begin{array}{c}\text { Total } \\
\text { Mean (SD) }\end{array}$ & $\begin{array}{c}\text { Regular } \\
\text { Mean (SD) }\end{array}$ & $\begin{array}{c}\text { Light } \\
\text { Mean (SD) }\end{array}$ & $\begin{array}{c}\text { Very Light } \\
\text { Mean (SD) }\end{array}$ & F & Sig \\
\hline Fish is easy to prepare and serve & $4.29(0.93)$ & $4.51(0.93)^{\mathrm{b}}$ & $4.26(0.92)^{\mathrm{a}}$ & $4.10(0.90)^{\mathrm{a}}$ & 15.6 & 0.00 \\
I can easily prepare tasty dishes & $4.17(1.01)$ & $4.39(1.04)^{\mathrm{b}}$ & $4.14(0.99)^{\mathrm{a}}$ & $4.00(0.97)^{\mathrm{a}}$ & 11.8 & 0.00 \\
from fish & & & & & & \\
I am familiar with preparing fish & $4.11(1.04)$ & $4.42(1.01)^{\mathrm{b}}$ & $4.01(1.02)^{\mathrm{a}}$ & $3.92(1.04)^{\mathrm{a}}$ & 20.3 & 0.00 \\
I am well informed about fish & $3.99(1.06)$ & $4.20(1.09)^{\mathrm{b}}$ & $3.87(1.01)^{\mathrm{a}}$ & $3.89(1.04)^{\mathrm{a}}$ & 9.5 & 0.00 \\
$\begin{array}{l}\text { I cannot recognise when fish is } \\
\text { fresh }\end{array}$ & $3.21(3.21)$ & $2.99(1.18)^{\mathrm{a}}$ & $3.32(1.11)^{\mathrm{b}}$ & $3.32(1.16)^{\mathrm{b}}$ & 8.2 & 0.00 \\
$\begin{array}{l}\text { I do not know much about how to } \\
\text { prepare and serve fish }\end{array}$ & $2.92(1.28)$ & $2.68(1.27)^{\mathrm{a}}$ & $2.97(1.20)^{\mathrm{b}}$ & $3.12(1.32)^{\mathrm{b}}$ & 9.6 & 0.00 \\
I do not know how to select fish & $2.83(1.18)$ & $2.59(1.19)^{\mathrm{a}}$ & $2.89(1.13)^{\mathrm{b}}$ & $3.01(1.16)^{\mathrm{b}}$ & 10.5 & 0.00 \\
\hline
\end{tabular}

(6 point scale: $6=$ strongly agree to $1=$ strongly disagree)

ANOVA F-tests with corresponding p-value

Different letters $(\mathrm{a}, \mathrm{b})$ indicate significantly different means using post hoc Tukey B tests

The majority of respondents (83\%), and older consumers (45 years plus) in particular $(\mathrm{F}(4,894)=10.0, \mathrm{p}=0.00)$, agreed that fish is easy to prepare and serve. Regular fish consumers were more likely to agree that fish is easy to prepare and serve than lighter fish consumers $(\mathrm{F}(2,896)=15.6, \mathrm{p}=0.00)$. Moreover, 78 percent of respondents, and males in particular $(\mathrm{t}=1.98$, d.f. $=897, \mathrm{p}<0.05)$ agreed with the statement "I can easily prepare tasty dishes from fish". Regular fish consumers were more likely to agree that they can easily prepare tasty dishes from fish than lighter fish consumers $(F(2,896)=11.8, p=0.00)$. In line with previous research findings (Verbeke \& Vackier, 2005), the majority of the respondents (75\%), and in particular older consumers (45 years plus) agreed that they are familiar with preparing fish $(\mathrm{F}(4,894)=12.1, \mathrm{p}=0.00)$. Regular fish consumers were more likely to agree that they are familiar with preparing fish than lighter fish consumers $(\mathrm{F}(2,896)=20.3, \mathrm{p}=$ $0.00)$. However, in contrast to previous studies where consumers have indicated being less informed about fish (e.g., Verbeke \& Vackier, 2005), more than two-thirds of the respondents in this study (69\%) agreed they are well informed about fish. Regular fish consumers were more likely to agree that they are well informed about fish than lighter fish consumers $(\mathrm{F}(2,896)=9.5, \mathrm{p}=0.00)$. In particular, younger consumers (under 25 years) were less likely to agree that they are informed about fish than older consumers $(55$ years plus) $(\mathrm{F}(4,894)=$ $5.4, \mathrm{p}=0.00)$.

Almost half of the respondents (41\%) agreed that they cannot recognise if fish is fresh, and this was particularly the case for females $(t=-2.00$, d.f. $=897, p<0.05)$ and younger consumers $(\mathrm{F}(4,894)=7.1, \mathrm{p}=0.00)$. Regular fish consumers were more likely to agree that they cannot recognise if fish is fresh than lighter consumers $(F(2,896)=8.2, p=0.00)$. Over one-third of respondents (34\%) acknowledged that they do not know much about how to prepare and serve fish. Very light fish consumers were more likely to agree that they do not know much about how to prepare or serve fish than either regular or light fish consumers $(\mathrm{F}(2,896)=9.6, \mathrm{p}=0.00)$. Moreover, about one-third of respondents $(29 \%)$ agreed that they do not know how to select fish. Females $(\mathrm{t}=-2.73$, d.f. $=897, \mathrm{p}<0.01)$ and consumers under 35 years of age $(\mathrm{F}(4,894)=13.2, \mathrm{p}=0.00)$ were more likely to agree that they do not know how to select fish than older consumers (45 years plus), and in line with previous studies (e.g., Verbeke et al. 2007; Vanhonacker et al., 2010) regular fish consumers were more likely to agree that they do not know how to select fish than lighter fish consumers $(\mathrm{F}(2,896)=10.5, \mathrm{p}$ $=0.00)$. 
In line with the literature, a lack of familiarity with preparing fish, being less informed about seafood and lack of knowledge and confidence in evaluating freshness, selecting and preparing seafood appear to add to functional risk, thus creating a significant barrier to fish consumption in Australia, in particular for lighter fish consumers (Fischer \& Frewer, 2009; Juhl \& Poulsen, 2000; Sogn-Grundvåg \& Ostli, 2009; Sveinsdóttir et al., 2009; Verbeke \& Vackier, 2005). Hence, Hypotheses 1 is supported.

\subsection{Findings related to the social risk of seafood consumption}

To determine the extent to which seafood consumption in Australia is influenced by social norms, we asked respondents their level of agreement with three statements about the influence of others in their household on household fish consumption (Table 4). Respondents were given a not applicable response category for this question, however a few people who were either living alone and/or did not have children living at home still responded to questions that were not applicable to their situation. Therefore, in the analysis we only included people who identified as not living alone for the two statements related to the presence of other household members and we only included people who identified as having children living at home for the item related to children not liking fish.

\section{Table 4}

Perceptions of factors associated with the social risk of fish consumption by usage segment.

\begin{tabular}{|c|c|c|c|c|c|c|}
\hline Item & $\begin{array}{c}\text { Total } \\
\text { Mean (SD) }\end{array}$ & $\begin{array}{c}\text { Regular } \\
\text { Mean (SD) }\end{array}$ & $\begin{array}{c}\text { Light } \\
\text { Mean (SD) }\end{array}$ & $\begin{array}{l}\text { Very Light } \\
\text { Mean (SD) }\end{array}$ & $\mathrm{F}$ & Sig \\
\hline $\begin{array}{l}\text { One or more children in my } \\
\text { household do not like fish }\end{array}$ & $3.00(1.57)$ & $2.76(1.54)$ & $3.00(1.62)$ & $3.21(1.51)$ & 2.8 & 0.06 \\
\hline $\begin{array}{l}\text { Resistance by other members of my } \\
\text { household make it hard for me to } \\
\text { serve fish as often as I want }\end{array}$ & $2.79(1.57)$ & $2.55(1.50)^{\mathrm{a}}$ & $2.81(1.58)^{\mathrm{ab}}$ & $3.02(1.59)^{\mathrm{b}}$ & 5.7 & 0.01 \\
\hline $\begin{array}{l}\text { Other adults in my household do } \\
\text { not like fish }\end{array}$ & $2.52(1.44)$ & $2.28(1.32)^{\mathrm{a}}$ & $2.59(1.53)^{\mathrm{b}}$ & $2.67(1.44)^{b}$ & 6.2 & 0.01 \\
\hline
\end{tabular}

(6 point scale: $6=$ strongly agree to $1=$ strongly disagree)

ANOVA F-tests with corresponding p-value

Different letters $(\mathrm{a}, \mathrm{b})$ indicate significantly different means at $\mathrm{p}<0.05$ using post hoc Tukey B tests

Over one-third of respondents with children living at home (36\%) agreed that one or more children in their household do not like fish. No significant differences across consumption segments were evident for this statement. However, people with teenagers living at home were more likely to agree that one or more children in their household do not like eating fish $(\mathrm{F}(4,410)=3.5, \mathrm{p}<0.01)$. In contrast to Verbeke and Vackier $(2005)$ who found that about one -quarter $(24 \%)$ of family members in their study of Belgian consumers did not want to eat fish, in this study, almost one-third (31\%) of respondents who were not living alone agreed that resistance by other members of their household makes it hard for them to serve fish as often as they want. Very light fish consumers were more likely to agree with this statement than regular fish consumers $(\mathrm{F}(2,749)=5.7, \mathrm{p}<0.01)$. In particular, and in keeping with previous studies (e.g., Myrland et al., 2000), respondents with teenagers or younger children (under 12 years) living at home were more likely to agree that they face resistance to serving fish $(\mathrm{F}(7,744)=8.9, \mathrm{p}=0.00)$. Only 21 percent of respondents who were not living alone agreed that other adults in their household do not like fish. Regular fish consumers were more likely to disagree with this statement than lighter fish consumers $(\mathrm{F}(2,782)=6.2, \mathrm{p}<0.01)$. Hence, social risks arising from the negative influence of 
household members appear to act to decrease seafood consumption in Australia; however this is less likely to be the case for regular fish consumers. Hence, Hypothesis 2 is supported.

\subsection{Findings related to the physical risk of seafood consumption}

Another potential barrier to seafood consumption relates to consumers' perceptions about the safety of seafood, including concerns about spoilage, contaminants, additives and hygienic handling. To explore these perceptions, we asked respondents to indicate their level of agreement about the perceived physical risks of consuming fish (Table 5).

\section{Table 5}

Perceptions of factors associated with the physical risk of fish consumption by usage segment.

\begin{tabular}{|c|c|c|c|c|c|c|}
\hline Item & $\begin{array}{l}\text { Total } \\
\text { Mean } \\
(\mathrm{SD})\end{array}$ & $\begin{array}{l}\text { Regular } \\
\text { Mean } \\
(\mathrm{SD})\end{array}$ & $\begin{array}{l}\text { Light } \\
\text { Mean } \\
(\mathrm{SD})\end{array}$ & $\begin{array}{l}\text { Very Light } \\
\text { Mean (SD) }\end{array}$ & $\mathrm{F}$ & Sig \\
\hline $\begin{array}{l}\text { I am concerned about high mercury levels } \\
\text { in fish }\end{array}$ & $4.02(1.18)$ & $4.07(1.31)$ & $4.09(1.11)$ & $3.91(1.12)$ & 2.3 & 0.11 \\
\hline $\begin{array}{l}\text { I am concerned about possible } \\
\text { contaminants in fish }\end{array}$ & $3.90(1.10)$ & $3.93(1.21)$ & $3.95(1.02)$ & $3.83(1.05)$ & 1.0 & 0.37 \\
\hline $\begin{array}{l}\text { I am concerned that fish may not have } \\
\text { been handled in a hygienic way }\end{array}$ & $3.67(1.08)$ & $3.70(1.14)$ & $3.66(1.07)$ & $3.66(1.03)$ & 0.2 & 0.85 \\
\hline $\begin{array}{l}\text { I am concerned that the fish may have } \\
\text { been treated with hormones and/or } \\
\text { antibiotics }\end{array}$ & $3.67(1.17)$ & $3.68(1.27)$ & $3.72(1.09)$ & $3.61(1.14)$ & 0.7 & 0.51 \\
\hline Eating fish is risky & $2.95(0.95)$ & $2.85(0.94)$ & $3.00(0.98)$ & $2.99(0.92)$ & 2.2 & 0.11 \\
\hline
\end{tabular}

(6 point scale: $6=$ strongly agree to $1=$ strongly disagree)

ANOVA F-tests with corresponding p-value

With respect to contaminants and additives, 70 percent of respondents, and females in particular $(\mathrm{t}=-2.5$, d.f. $=897, \mathrm{p}<0.02)$, agreed they are concerned about high mercury levels in fish. More educated respondents with either a tertiary education or a technical qualification were more likely to agree that they were concerned about mercury levels in fish than less educated people with either a secondary or primary school education $(\mathrm{F}(3,895)=3.7, \mathrm{p}=$ $0.01)$. More than two-thirds of respondents $(68 \%)$, and once again females in particular $(\mathrm{t}=-$ 1.5 , d.f. $=897, \mathrm{p}<0.02$ ), agreed that they are concerned about possible contaminants in fish. Over half of the respondents (59\%) agreed that they are concerned that fish may not have been handled in a hygienic way. Just over half of the respondents $(55 \%)$ agreed that they are concerned that the fish may have been treated with hormones and/or antibiotics. Nearly onequarter of the respondents $(24 \%)$, and in particular females $(\mathrm{t}=-2.5$, d.f. $=897, \mathrm{p}<0.02)$, agreed that eating fish is risky. However, analysis of variance did not reveal any significant differences across consumption segments with respect to the physical risks of seafood consumption, and thus Hypothesis 3 is not supported.

\subsection{Findings related to the psychological risk of seafood consumption}

To assess the perceived psychological risk of seafood consumption, we asked respondents their level of agreement with a number of statements, as presented in Tables 6 and 7. Factor analysis revealed that two separate types of psychological risk are associated with seafood consumption. The first factor relates to 'unpleasant past experiences' with seafood consumption, while the second factor concerns the 'unpleasant sensory qualities' experienced when preparing and consuming seafood. 


\section{Table 6}

Perceptions of factors associated with the psychological risks of fish consumption related to past experiences by usage segment.

\begin{tabular}{lcccccc}
\hline \multicolumn{1}{c}{ Item } & $\begin{array}{c}\text { Total } \\
\text { Mean (SD) }\end{array}$ & $\begin{array}{c}\text { Regular } \\
\text { Mean (SD) }\end{array}$ & $\begin{array}{c}\text { Light } \\
\text { Mean (SD) }\end{array}$ & $\begin{array}{c}\text { Very Light } \\
\text { Mean (SD) }\end{array}$ & F & Sig \\
\hline $\begin{array}{l}\text { I have had good experiences in } \\
\text { eating fish in the past }\end{array}$ & $4.66(0.93)$ & $4.80(0.92)^{\mathrm{b}}$ & $4.63(0.94)^{\mathrm{a}}$ & $4.54(0.90)^{\mathrm{a}}$ & 6.3 & 0.02 \\
$\begin{array}{l}\text { Eating fish is usually an unpleasant } \\
\text { experience }\end{array}$ & $1.95(1.13)$ & $1.87(1.21)$ & $1.97(1.15)$ & $2.02(1.04)$ & 1.4 & 0.24 \\
Fish usually tastes bad & $1.89(0.96)$ & $1.74(0.94)^{\mathrm{a}}$ & $1.93(0.99)^{\mathrm{b}}$ & $1.98(0.98)^{\mathrm{b}}$ & 5.0 & 0.01 \\
\hline
\end{tabular}

(6 point scale: $6=$ strongly agree to $1=$ strongly disagree)

ANOVA F-tests with corresponding p-value

Different letters $(\mathrm{a}, \mathrm{b})$ indicate significantly different means using post hoc Tukey B tests

The majority of respondents (93\%) agreed that they have had good experiences in eating fish in the past, and 91 percent, and older people in particular $(\mathrm{F}(4,894)=4.1, \mathrm{p}<$ 0.05), disagreed that "Eating fish is usually an unpleasant experience". Regular fish consumers were more likely to agree that they have had good experiences in eating fish in the past than lighter fish consumers $(\mathrm{F}(2,896)=6.3, \mathrm{p}=0.02)$. More educated respondents with either a tertiary education or a technical qualification were less likely to agree that eating fish is usually an unpleasant experience than people with a secondary school education $(\mathrm{F}(3,895)$ $=3.5, \mathrm{p}=0.01)$. Only five percent of respondents, and younger people in particular $(\mathrm{F}(4,894)$ $=10.7, p=0.00)$ agreed with the statement "Fish usually tastes bad". Regular fish consumers were less likely to agree that fish usually tastes bad than lighter fish consumers $(\mathrm{F}(2,896)=$ $5.0, \mathrm{p}=0.01)$.

\section{Table 7}

Perceptions of factors associated with the psychological risks of fish consumption related to unpleasant sensory qualities by usage segment.

\begin{tabular}{lllllll}
\hline & Total & Regular & Light & Very Light & F & Sig \\
Item & Mean (SD) & Mean (SD) & Mean (SD) & Mean (SD) & & \\
\hline $\begin{array}{l}\text { The bones in fish are unpleasant } \\
\text { I do not like the smell of fish when } \\
\text { preparing it }\end{array}$ & $4.54(1.31)$ & $4.52(1.30)$ & $4.56(1.35)$ & $4.54(1.29)$ & 0.5 & 0.95 \\
I do not like the smell of fish & $3.10(1.29)$ & $2.97(1.38)$ & $3.11(1.27)$ & $3.21(1.22)$ & 2.5 & 0.08 \\
I do not like to touch fish & & & & & & \\
\hline
\end{tabular}

(6 point scale: $6=$ strongly agree to $1=$ strongly disagree)

ANOVA F-tests with corresponding p-value

Different letters $(\mathrm{a}, \mathrm{b})$ indicate significantly different means at $\mathrm{p}<0.05$ using post hoc Tukey B tests

The majority of respondents (84\%) agreed that "the bones in fish are unpleasant", however this negative perception did not influence consumption rate. In a study of Belgian consumers, Verbeke and Vackier (2005) also found that while respondents held a negative attitude towards bones in fish, this did not influence behavioural intentions. Over one-third of the respondents $(38 \%)$ agreed that they do not like the smell of fish when preparing it and nearly half of the respondents $(43 \%)$, and females $(t=-3.6$, d.f. $=897, p=0.00)$ and younger people in particular $(\mathrm{F}(4,894)=7.5, \mathrm{p}=0.00)$, agreed with the statement, "I do not like the smell of fish". Only 27 percent of respondents agreed with the statement, "I do not like the touch of fish". Females $(t=-3.97$, d.f. $=897, \mathrm{p}=0.00)$ and younger $(\mathrm{F}(4,894)=8.61, \mathrm{p}=$ $0.00)$ respondents were more likely to agree that they do not like the touch of fish than males 
or older respondents. Very light fish consumers were more likely to agree that they do not like to touch fish than either regular or light fish consumers $(\mathrm{F}(2,896)=6.9, \mathrm{p}=0.00)$.

Hence, consistent with previous studies of fish consumption, unpleasant past experiences with fish may add to psychological risk and negatively impact on fish consumption in Australia. Moreover, the findings revealed that lighter fish consumers are more likely to report unpleasant past experiences with fish and very light fish consumers are more concerned about touching fish. Hence, Hypothesis 4 is supported.

\subsection{Findings related to the financial risk of seafood consumption}

To uncover consumers' perceptions regarding the financial risks associated with seafood consumption we asked respondents for their level of agreement on one statement. In line with European studies (e.g., Brunsø et al., 2009; Vanhonacker et al., 2010), over half of the respondents $(52 \%)$ tended to agree that fish is an expensive meal option, with 48 percent of the respondents $(\mu=3.44, \mathrm{SD}=1.24)$ agreeing with the statement "Fish is an inexpensive meal option”. However, analysis of variance did not reveal any differences across consumption segments. Verbeke and Vackier (2005) also found that price was a major barrier to fish consumption; however it did not reduce behavioural intention to consume fish. Analysis of variance did not reveal any significant differences in price perceptions based on income. This was in contrast to a study conducted by Myrland et al. (2000) where income level was found to be negatively associated with price perceptions. However in keeping with the study by Myrland et al. (2000), differences in consumption rate (regular, light or very light) were not influenced by perceptions of price. Hence, Hypothesis 5 is not supported.

\subsection{Implications and potential strategies for overcoming barriers to purchase}

The empirical findings of this study reveal that perceptions of functional, physical, social, psychological and financial risk create barriers to seafood consumption in Australia, and with the exception of physical and financial risk, higher perceptions of risk are experienced by lighter seafood consumers as compared with more regular seafood consumers. While key drivers of seafood consumption including taste, convenience, variety and perceived health benefits should be leveraged to strengthen their facilitating effects, further strategies aimed at reducing perceived risks and attenuating inhibitory effects, in particular for lighter consumers, require further investigation (Birch \& Lawley, 2010; Scholderer \& Grunert, 2001).

In line with the literature, a lack of familiarity with preparing seafood, being less informed about fish, and a lack of knowledge and confidence in evaluating freshness, selecting and preparing seafood appear to add to functional risk, thus creating a significant barrier to fish consumption in Australia (Fischer \& Frewer, 2009; Juhl \& Poulsen, 2000; Sogn-Grundvåg \& Ostli, 2009; Sveinsdóttir et al., 2009; Verbeke \& Vackier, 2005). Moreover, the findings of this study indicate that lighter seafood consumers, females and younger consumers perceive higher levels of risk. This highlights the need for increased, more targeted and trustworthy consumer education and information including for example, tips for selecting and storing seafood, easy step by step instructions for preparing seafood, recipes and serving suggestions (Vanhonacker et al., 2010). Of greatest concern to the Australian seafood industry is that almost half of the respondents $(41 \%)$ in this study indicated that they cannot recognise if fish is fresh. This problem is exacerbated due to the absence of use by dates for fresh chilled seafood in the delicatessen section of the supermarket and at fishmongers, as well as, a general lack of transparency about or knowledge regarding days-since-catch/farmed and whether the seafood has previously been frozen (Fischer \& Frewer, 2009). For example, Fischer and Frewer (2009) found that the 
provision of days-since-catch information was valued by consumers when evaluating the freshness, quality and tenderness of fish. Compounding this problem, studies have revealed that people who experience greater difficulties with selecting and preparing fish are also less involved and less likely to be interested in, or to use, information (Vanhonacker et al., 2010; Verbeke et al., 2007). Moreover, socio-demographic differences associated with the use and trust of information sources about fish have been identified on the bases of gender, age and education levels (Pieniak et al., 2007b). Hence, in addition to determining what education and information lighter seafood consumers may find useful, it is also important to adopt a more targeted approach and determine where (e.g., message channels and media vehicles), how (e.g., message strategies, appeals and message structure), and by whom (e.g., personal versus non-personal sources, commercial versus non-commercial sources) that information would be best delivered to actually reach and influence the intended audience (Pieniak et al., 2007b).

Given the lack of confidence some consumers experience with cooking seafood, Vanhonacker et al. (2010, p. 179) suggested the provision of 'ready-made fish dishes or fish finger-type products' for less experienced fish consumers. For example, the popularity of frozen crumbed fish fillets for dinner or tuna in a snack-size ( 85 gram) rip-top canned format for lunch in Australia is testament to the acceptance of more convenient seafood offerings. However, given the failure of some ready-made seafood products to influence intended target markets, any new product development should be undertaken in a systematic manner involving a stage-gate approach, whereby consumers are involved in the generation of new product ideas, and concepts are thoroughly tested before being launched into the market (Cooper, 2008; Olsen, Heide, Dopico, \& Toften, 2008).

Previous studies of seafood consumption have indicated that social norms or acceptability to family and friends negatively influence fish consumption (Olsen, 2001; Olsen, 2004; Scholderer \& Grunert, 2001; Trondsen et al., 2003 Verbeke \& Vackier, 2005). Likewise, Australian consumers appear to be negatively influenced by members of their household, and by teenagers and younger children in particular, with respect to seafood consumption. The Australian seafood industry may be able to reduce the negative impact of social norms for these consumers by developing seafood products that are more acceptable to all members of the family (e.g., products without bones or fish odour). Given a strong sense of moral obligation to serve seafood to the household, due to its significant health benefits and the provision of a varied diet, marketing messages with moral appeals and greater emphasis on the health benefits of seafood and delivering a balanced diet for family members may also serve to reduce social risk (Olsen 2001; Verbeke \& Vackier, 2005). Moreover, providing interesting, fun and engaging information and education on seafood and how to prepare seafood through the use of humorous appeals may be more appealing to all members of the family and thus serve to reduce negative influences associated with social norms. For example, Scholderer and Grunert (2001) found that a television campaign featuring two wellknown comedians focusing on the fact that tasty fish dishes are easy and convenient to prepare reduced the negative impacts of perceived lack of availability of fresh fish and lack of meal preparation skills on purchase intention and consumption. Moreover, it had a positive impact on family norms, in terms of the main household shopper perceiving an increased demand from their family to serve fish.

In keeping with European studies of seafood consumption (e.g., Fischer \& Frewer, 2009; Sioen et al., 2008; Verbeke et al., 2005), some Australian consumers, and females in particular, are concerned about the safety of seafood; however, perceptions of physical risk associated with seafood consumption did not differ across consumption segments. Perceptions of physical risk included concerns about high mercury levels, possible contaminants, treatment with hormones or antibiotics, and whether the seafood has been handled in a hygienic manner. Strategies for reducing the perceived physical risks of fish 
consumption would involve providing scientifically accurate and trustworthy information on the physical risks of seafood consumption, and in particular the higher risk associated with some species (Knuth, Connelly, Sheeshka, \& Patterson, 2003; Pieniak et al., 2008; Verbeke et al., 2008). However, the order of arguments presented in the information needs to be carefully considered, as Fischer and Frewer (2009) found a primacy effect whereby information provided first was most influential when evaluating unfamiliar products, such as fish. Given that Australian consumers hold very positive attitudes toward seafood and understand the significant health benefits of seafood, messages emphasising the health benefits of seafood before addressing any potential hazards may outweigh any perceptions of physical risk. Moreover, Australian consumers may seek to reduce physical risk by using valued extrinsic cues on seafood labelling and point of sale displays such as use-by dates, branding and nutritional information, and they may be prepared to pay for assurances of quality, for example, quality certification and traceability information such as region and method of production (Angulo \& Gil, 2007; Dimara \& Skuras, 2003; Fischer \& Frewer, 2009; Pieniak et al., 2007b). Indeed, this information at the point of sale may serve the heuristic function, facilitating easier decision making for time-poor consumers (Pieniak et al., 2007b). Conversely, some information elements may be misinterpreted or distorted due to limited consumer knowledge and understanding (e.g., the true meaning of various sustainability claims), while too much information may result in cognitive overload resulting in confusion or indifference or lead to selective attention with only information that confirms existing attitudes being noticed (Pieniak et al., 2007b).

Psychological barriers related to past experiences with seafood consumption in Australia appear to be minimal, with the majority of consumers reporting good experiences with consuming seafood in the past. Perceptions of unpleasant sensory qualities associated with the preparation of fish such as smell, touch and bones were more evident with very light fish consumers, with females, in particular, not liking the smell of fish or to touch fish. The development of seafood products without bones or smell or ready-made products that do not require consumers to touch the fish may reduce the psychological risk associated with unpleasant sensory qualities (Olsen, 2001).

Finally, more than half of the respondents in this study consider seafood to be a relatively expensive meal option. Price is frequently cited as the major barrier to seafood consumption (Brunsø et al., 2009; Myrland et al., 2000; Olsen, 2004; Trondsen et al., 2003; Verbeke \& Vackier, 2005). Strategies for reducing the perceived expensiveness of seafood need to be more fully explored and could include smaller portion sizes with price per portion information, as well as, encouraging Australian consumers to eat more of the less expensive, less popular and under-valued seafood species. However, this may prove difficult due to preference for familiar foods, higher risks associated with unfamiliar versus familiar foods and the presence of consumption circles or consideration sets, in which consumers tend to recycle a limited repertoire of tried and tested recipes (Fischer \& Frewer, 2009; Rortveit \& Olsen, 2007).

\section{Limitations and future research}

This study investigated barriers to seafood consumption in Australia, with the focus of this paper being on perceived risks of seafood consumption. Possible strategies for reducing perceptions of risk and thus stimulating seafood consumption have been identified. Future studies may investigate specific strategies or interventions designed to reduce perceived functional, social, physical, psychological and financial risk and measure impact on consumption intentions and/or frequency. 
The sample for this study was positively skewed with respect to age and education, and given that older and more educated consumers tend to perceive fewer barriers to seafood consumption, perceived risks and barriers may be under-reported in this study. With the exception of more educated respondents perceiving greater concerns regarding mercury levels in fish and being less likely to consider fish to be an unpleasant experience, we identified no other statistically significant differences based on educational levels. Future studies should seek to include more people from younger age groups and lower educational levels as these cohorts are more likely to be lighter seafood consumers, and thus are of greater concern with respect to seafood consumption. Moreover, given concerns in other western countries regarding low levels of seafood consumption, future studies could involve comparative studies including other western countries, such as the United States, United Kingdom and New Zealand.

\section{Conclusions}

Australian consumers perceive a number of risks associated with seafood consumption including functional, social, physical, psychological and financial risks. These risks arise from a lack of familiarity, knowledge and confidence in selecting and preparing seafood, as well as, the negative influence of household members over seafood consumption, unpleasant sensory qualities associated with fish, and concerns regarding the safety of fish. With the exception of physical and financial risks, these risks vary across consumption segments with regular fish consumers perceiving fewer barriers to seafood consumption than lighter fish consumers. In an attempt to reduce the level of perceived risk, consumers may prefer familiar over unfamiliar seafood products, seek out trustworthy and accurate information, or be more reliant on extrinsic cues and be willing to pay for assurances of quality and origin. The challenge for the Australian seafood industry is to build consumer trust and seek to reduce the perceived risk of seafood consumption by more strategically informing and educating consumers on how to more effectively select, store and prepare fish and providing Australian consumers with sufficient, trustworthy and valuable information and assurances at the point of sale and on seafood packaging. Based on the understanding of barriers to seafood consumption in Australia arising from this study, future research should focus on identifying and testing strategies and interventions for stimulating seafood consumption in Australia.

\section{Acknowledgements}

This work formed part of a project of the Australian Seafood Cooperative Research Centre, and received funds from the Australian Government's CRCs Programme, the Fisheries R\&D Corporation and other CRC Participants. 


\section{References}

Angulo, A. M., \& Gil, J. M. (2007). Risk perception and consumer willingness to pay for certified beef in Spain. Food Quality and Preference, 18, 1106-17.

Arvanitoyannis, I. S., \& Krystallis, A. (2005). Consumers' beliefs, attitudes and intentions towards genetically modified foods, based on the perceived safety vs. benefits' perspective. International Journal of Food Science and Technology, 40, 343-60.

Australian Bureau of Statistics (2011). Census data [www page]. URL http://www.abs.gov.au/websitedbs/censushome.nsf/home/Data

Baird, P. D., Bennett, R., \& Hamilton, M. (1988). The consumer acceptability of some underutilised fish species. In D.M.H. Thomsen (Ed.) Food acceptability (pp. 431-42). London: Elsevier Applied Science.

Bandura, A. (1997). Self-efficacy: The exercise of control. New York: W.H. Freeman.

Bansal, H. S., \& Voyer, P. A. (2000). Word-of-mouth processes within a services purchase decision context. Journal of Service Research, 3, 166-177.

Bauer, R. A. (1960). Consumer behaviour as risk taking. In R. S. Hancock (Ed.), Dynamic marketing for a changing world. Proceedings of the $43^{\text {rd }}$ Conference of the American Marketing Association, Chicago, Illinois (pp. 389-98).

Bean, N. H., \& Griffen, P. M. (1990). Food borne disease outbreaks in the United States, 1973-1987: Pathogens, vehicles and trends. Journal of Food Protection, 5, 804-18.

Bettman, J. R. (1973). Perceived risk and its components: A model and empirical test. Journal of Marketing Research, 10, 184-90.

Birch, D., \& Lawley, M. (2010). Repositioning Australian Farmed Barramundi: Online Consumer Survey Findings, Australian Seafood Cooperative Research Centre and the University of the Sunshine Coast, September 2010.

Blackwell, R. D., Miniard, P. W., \& Engel, J. F. (2001). Consumer behaviour. (9 ${ }^{\text {th }}$ ed.). Fort Worth, Texas: Harcourt.

Bredbenner, C. B., Mauer, J., Wheatly, V., Cottone, E., \& Clancy, M. (2007). Observed food safety behaviours in young adults. British Food Journal, 109, 519-30.

Bredahl, L., \& Grunert, K. G. (1997). Determinants of the consumption of fish and shellfish in Denmark: An application of the theory of planned behaviour. In J.B. Luten, T. Borresen, \& J. Oehlenschlager (Eds.), Fish from producer to consumer, integrated approach to quality (pp. 21-30). Amsterdam: Elsevier.

Bruns $\varnothing$, K., Verbeke, W., Olsen, S. O., \& Jeppesen, L. F. (2009). Motives, barriers and quality evaluation in fish consumption situations: exploring and comparing heavy and light users in Spain and Belgium. British Food Journal, 111, 699-716. 
Campbell, M. C., \& Goldstein, R. C. (2001). The moderating effect of perceived risk on consumers' evaluations of product incongruity: Preference for the norm. Journal of Consumer Research, 28, 439-49.

Chen, M. F., \& Li, H. L. (2007). The consumer's attitude toward genetically modified foods in Taiwan. Food Quality and Preference, 18, 662-74.

Cho, J., \& Lee, J. (2006). An integrated model of risk and risk-reducing strategies. Journal of Business Research, 59, 112-20.

Cooper, R. G. (2008). Perspective: The stage-gate idea to launch process - Update, what's new and NexGen systems. Journal of Product Innovation Management, 25, 213-232.

Cunningham, S. M. (1967). The major dimensions of perceived risk. In D. F. Cox (Ed.), Risk taking and information handling in consumer behavior (pp. 82-108). Boston, MA: Harvard University Press.

Danenberg, N., \& Mueller, S. (2011). Omnibus Consumer Research Findings - Wave 2, Australian Seafood Cooperative Research Centre and the UniSA Ehrenberg-Bass Institute for Marketing Science, May 2011.

Dimara, E., \& Skuras, D. (2003). Consumer evaluations of product certification, geographic association and traceability in Greece. European Journal of Marketing, 37, 690 - 705.

Dowling, G. R., \& Staelin, R. (1994). A model of perceived risk and intended risk-handling activities. Journal of Consumer Research, 21, 119-34.

Fischer, A. R. H., \& Frewer, L. J. (2009). Consumer familiarity with foods and the perception of risks and benefits. Food Quality and Preference, 20, 576-85.

Fisheries Research \& Development Corporation (2006). Retail sale and consumption of fish. Melbourne.

Foxall, G., Leek, S., \& Maddock, S. (1998). Cognitive antecedents of consumers' willingness to purchase fish rich in polyunsaturated fatty acids (PUFA). Appetite, 31, 391-402.

Frewer, L. J., Shepherd, R., \& Sparks, P. (1994). The interrelationships between perceived knowledge, control and risk associated with a range of food-related hazards targeted at the individual, other people and society. Journal of Food Safety, 14, 19-40.

Garland, R. (1991). The mid-point on a rating scale: Is it desirable? Marketing Bulletin, 2, 6670.

Grewal, D., Gopalkrisnan, R. I., Gotlieb, J., \& Levy, M. (2007). Developing a deeper understanding of post-purchase perceived risk and behavioural intentions in a servicesetting. Journal of the Academy of Marketing Science, 35, 250-8.

Gurhan-Canli, Z., \& Batra, R. (2004). When corporate image affects product evaluations: the moderating role of perceived risk. Journal of Marketing Research, 41, 197-205. 
Hanson, G.D., Rauniyar, G. P., \& Herrmann, R. O. (1994). Using consumer profiles to increase the United States market for fish: Implications for aquaculture. Aquaculture, 127, 303-16.

Heart Foundation (2012). Food and nutrition facts [www page]. URL http://www.heartfoundation.org.au/healthy-eating/food-and-nutritionfacts/Pages/seafood.aspx

Honkanen, P., Olsen, S. O., \& Myrland, Ø. (2004). Preference-based segmentation: A study of meal preferences among Norwegian teenagers. Journal of Consumer Behaviour, 3, 235-50.

Howard, J. A., \& Sheth, J. N. (1969). The theory of buyer behaviour. New York: John Wiley $\&$ Sons.

Jardine, T. D., \& Bunn, S. E. (2010). Northern Australia, whither the mercury? Marine and Freshwater Research, 61, 451-63.

Juhl, H. J., \& Poulsen, C. S. (2000). Antecedents and effects of consumer involvement in fish as a product group. Appetite, 34, 261-7.

Klerch, D., \& Sweeney, J. (2007). The effects of knowledge types on consumer-perceived risk and adoption of genetically modified foods. Psychology and Marketing, 24, 17193.

Knight, F.H. (1948). Risk, uncertainty and profit. Boston, MA: Houghton-Mifflin.

Knuth, B.A., Connelly, N.A., Sheeshka, J., \& Patterson, J. (2003). Weighing health benefit and health risk information when consuming sport-caught fish. Risk Analysis, 23, $1185-1197$.

Laroche, M., Nepomuceno, M. V., \& Richard, M. (2010). How do involvement and product knowledge affect the relationship between intangibility and perceived risks for brands and product categories? Journal of Consumer Marketing, 27, 197-210.

Laurent, G., \& Kapferer, J.N. (1985). Measuring consumer involvement profiles. Journal of Marketing Research, 22, 41-53.

Leek, S., Maddock, S., \& Foxall, G. (2000). Situational determinants of fish consumption. British Food Journal, 102, 18-39.

Lobb, A. E., Mazzocchi, M., \& Traill, W. B. (2007). Modelling risk perception and trust in food safety information within the theory of planned behaviour. Food Quality and Preference, 18, 384-95.

Mahon, D., Cowan, C., \& McCarthy, M. (2006). The role of attitudes, subjective norms, perceived control and habit in the consumption of ready made meals and takeaway in Great Britain. Food Quality and Preference, 17, 474-81.

Malhotra, N.K. (2004). Marketing research: an applied orientation (4th ed.). Upper Saddle River, New Jersey: Prentice Hall. 
McCathy, M., \& Henson, S. (2005). Perceived risk and risk reduction strategies in the choice of beef by Irish consumers. Food Quality and Preference, 16, 435-45.

Mitchell, V-W. (1999). Consumer perceived risk: conceptualisations and models. European Journal of Marketing, 33, 163-95.

Myrland, Ø., Trondsen, T., Johnston, R. S., \& Lund, E. (2000). Determinants of fish consumption in Norway: Lifestyle, revealed preferences, and barriers to consumption. Food Quality and Preference, 11, 169-88.

Nielsen, J., Hyldig, G., \& Larsen, E. (2002). Eating quality of fish: A review. Journal of Aquatic Food Product Technology, 11 (3/4), 125-41.

Olsen, S. O. (2001). Consumer involvement in fish as family meals in Norway: An application of the expectancy-value approach. Appetite, 36, 173-86.

Olsen, S. O. (2003). Understanding the relationship between age and fish consumption: The mediating role of attitude, health involvement and convenience. Food Quality and Preference, 14, 199-209.

Olsen, S. O. (2004). Antecedents of fish consumption behavior: An overview. Journal of Aquatic Food Product Technology, 13 (3), 79-91.

Olsen, S.O., Heide, M., Dopico, D. C., \& Toften, K. (2008). Explaining intention to consume a new fish product: A cross-generational and cross-cultural comparison. Food Quality and Preference, 19, 618-627.

Olsen, S. O., \& Ruiz, S. (2008). Adolescents' influence in family meal decisions. Appetite, 51, 646-53.

Park, J., Lennon, S., \& Stoel, L. (2005). Online-product presentation: Effects on mood, perceived risk and repurchase intentions. Psychology and Marketing, 22, 695-719.

Pieniak, Z., Verbeke, W., Vermeir, I., Bruns $\varnothing$, K., \& Olsen, S. O. (2007a). Consumer interest in fish information and labelling. Journal of International Food \& Agribusiness Marketing, $19(2 / 3), 117$ - 41.

Pieniak, Z., Verbeke, W., Vermeir, I., Bruns $\varnothing$, K., \& Olsen, S. O. (2007b). European consumers' use of and trust in information sources about fish. Food Quality and Preference, 18, 1050-1063.

Pieniak, Z., Verbeke, W., Vermeir, I., Brunsø, K., \& Olsen, S. O. (2008). Impact of consumers' health beliefs, involvement and risk perception on fish consumption: A study in five European countries. British Food Journal, 110, 898-915.

Rortveit, A. W., \& Olsen, S. O. (2007). The role of consideration set in explaining fish consumption. Appetite, 49, 214-222.

Scholderer, J., \& Grunert, K. G. (2001). Does generic advertising work? A systematic evaluation of the Danish campaign for fresh fish. Aquaculture Economics \& Management, 5, 253 - 71. 
Sioen, I., Van Camp, J., Verdonck, F., Verbeke, W., Vanhonacker, F., \& Willems, J. (2007). Probabilistic intake assessment of multiple compounds as a tool to quantify the nutritional-toxicological conflict related to fish consumption. Chemosphere, 71, 105666.

Sogn-Grundvåg, G., \& Østli, J. (2009). Consumer evaluation of unbranded and unlabelled food products: The case of Bacalhau. European Journal of Marketing, 43, 213-28.

Sørensen, E., Grunert, K. G., \& Nielsen, N. A. (1996). The impact of product experience, product involvement and verbal processing style on consumers" cognitive structure with regard to fresh fish. MAPP working paper no. 42, The Aarhus School of Business.

Stone, R. N., \& Gronhaug, K. (1993). Perceived risk: Further considerations for the marketing discipline. European Journal of Marketing, 27, 39-50.

Sveinsdóttir, K., Martinsdóttir, E., Green-Petersen, D., Hyldig, G., Schelvis, R., \& Delahunty, C. (2009). Sensory characteristics of different cod products related to consumer preferences and attitudes. Food Quality and Preference, 20, 120-32.

Taylor, J.W. (1974). The role of risk in consumer behaviour. Journal of Marketing, 38 (2), 54-60.

Trondsen, T., Scholderer, J., Lund, E., \& Eggen, A. E. (2003). Perceived barriers to consumption of fish among Norwegian women. Appetite, 41, 301-14.

Tsiros, M., \& Heilman, C. M. (2005). The effect of expiration dates and perceived risk in purchasing behaviour in grocery store perishable categories. Journal of Marketing, 69 (2), 114-29.

Tuu, H. H., \& Olsen, S. O. (2009). Food risk and knowledge in the satisfaction-repurchase loyalty relationship. Asia Pacific Journal of Marketing and Logistics, 21, 521-36.

Vanhonacker, F., Pieniak, Z., \& Verbeke, W. (2010). Fish Market Segmentation Based on Consumers' Motives, Barriers and Risk Perception in Belgium. Journal of Food Products Marketing, 16, 166-83.

Verbeke, W., Sioen, I., Pieniak, Z., Van Camp, J., \& De Henauw, S. (2005). Consumer perception versus scientific evidence about health benefits and safety risks from fish consumption. Public Health Nutrition, 8, 422-9.

Verbeke, W., \& Vackier, I. (2005). Individual determinants of fish consumption: application of the theory of planned behaviour. Appetite, 44, 67-82.

Verbeke, W., Vanhonacker, F., Frewer, L. J., Sioen, I., De Henauw, S., \& Van Camp, J. (2008). Communicating risks and benefits from fish consumption: Impact on Belgian consumers' perception and intention to eat fish. Risk Analysis, 28, 951-967.

Verbeke, W., Vermeir, I., \& Brunsø, K. (2007). Consumers' evaluation of fish quality as basis for fish market segmentation. Food Quality and Preference, 18, 651-61. 
Your Source (2010). Your source panel: Many voices, managed with care [www page]. URL http://www.yrsource.com/ourpanel.html

Yuksel, A., \& Yuksel, F (2006). Shopping risk perception: effects on tourist's emotion, satisfaction and expressed loyalty intention. Tourism Management, 28, 303-13.

Zaichowsky, J. L. (1985). Measuring the Involvement Construct. Journal of Consumer Research, 12, 341-352. 